\title{
An Enriched Artifacts Activity for Supporting Creative Learning: Perspectives for Children with Impairments
}

\author{
Michail N. Giannakos and Letizia Jaccheri \\ Norwegian University of Science and Technology (NTNU), Trondheim, Norway \\ \{michailg, letizia\}@idi.ntnu.no
}

\begin{abstract}
In this paper we present the results of a creative development pro-gram for young students with the name, OurToys. In our empirical evaluation, a group of researchers and artists designed and implemented two workshop pro-grams of a total of 66 pupils, exploring their experiences with open source software and hardware. The workshops were based on Reggio Emilia philoso-phy of creative reuse and the open-source software Scratch. The results showed that: software and hardware intensive activities raise awareness of technology, intensify the experience, and invite students to explore boundaries and increase collaboration and the exchange of views and ideas.
\end{abstract}

Keywords: Creative activities, empirical evaluation, software and hardware development, physicaldigital creativity.

\section{Introduction}

Digital artifacts that enable people to exchange, create, and distribute information have, in the past couple of decades, profoundly reshaped the way we work and live [1] [4]. Artifacts allow children to learn by iteratively testing and rebuilding their designs [2]. The interactions between the children and the artifacts in a creative activi-ty are vital [5]. A better understanding of several aspects from childrens perspective could be valuable in designing effective creative activities. The purpose of the re-search presented in this paper is to build an understanding of the main interactions between children and the tools in creative activities and to consider improvements on the current processes. The clarification of this goal is expected to contribute to the understanding of how children face these activities and might increase their willing-ness to enroll in them.

This paper focuses on our efforts to develop an authentic environment for creative learninga workshop program (called OurToys) that helps school children, to build their own digital game/story based on physical objects. We believe OurToys repre-sents a good example of novel directions in the creative learning. In particular, in this paper we present experiences from designing and conducting

1 http://ourtoysntnu.wordpress.com/ 
the workshop program where children collaboratively engaged in creating interactive artworks that react to events in the physical world [6]. Children used the open source software Scratch, Arduino sensors, and recycled materials.

\section{OurToys: An Approach to Enhance Creative Learning}

In our approach, we designed and developed a workshop program with the name: OurToys. OurToys was based on open source software and hardware and consisted of tutorials on open source tools, artifacts enriched creative sessions and students demonstrations/presentations. Up to date, OurToys has organized five workshops (Figure 1, top left). The number of children who participated on each workshop was among 10 to 15 (Figure 1, top left). Most of the children who participated in the pro-ject were 12 years old (except the last one), and on each workshop we had groups (comprised of 2-4 children).

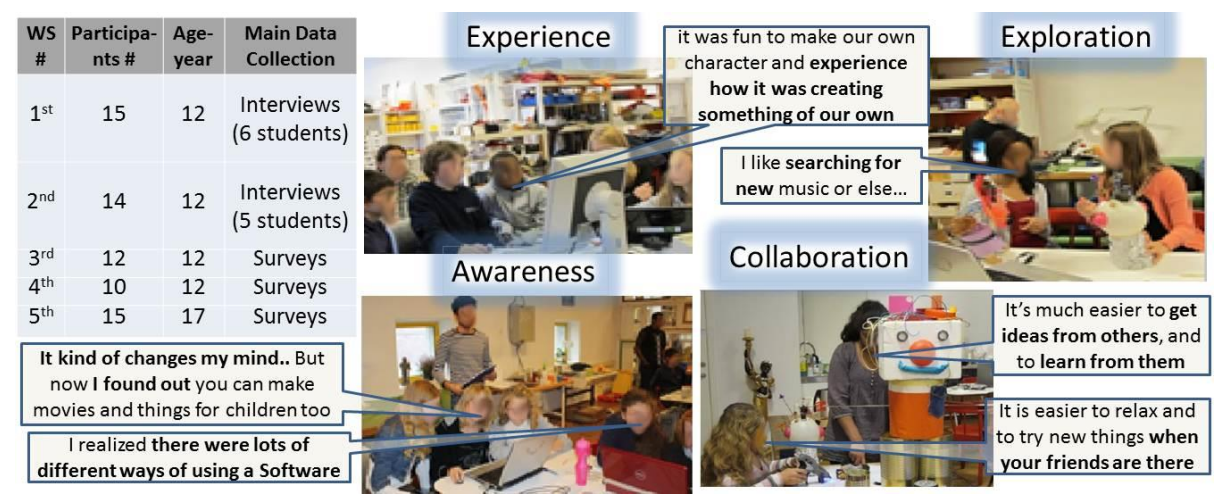

Fig. 1. The list of our field studies (top left); examples of children's responses

OurToys took place at creative centers of University and ReMida center, ReMida is a center that collects and offers a variety of materials for use in creative and educa-tional projects. The center is a cooperation between the municipality, the education project Reggio Children, the municipal waste company (recycling) and the local busi-ness community. Students worked according to Reggio Emilia education principles [3], where the main idea is that the initiative for creative actions should spring from the child himself/herself and the child takes different kinds of leadership roles at dif-ferent times. ReMida centers are creative places with a lot of appealing objects where children start to work without being activated by adults (Figure 2, left). The adults act as assistants.

Children attending the workshops were instructed and assisted by programming artist, the leader of the ReMida center, and 5 HCI researchers. During the whole workshop at least three members from them were present. Children use Scratch (S4A 2 ) software and Arduino boards to animate the physical characters

2 http://seaside.citilab.eu/scratch/arduino 

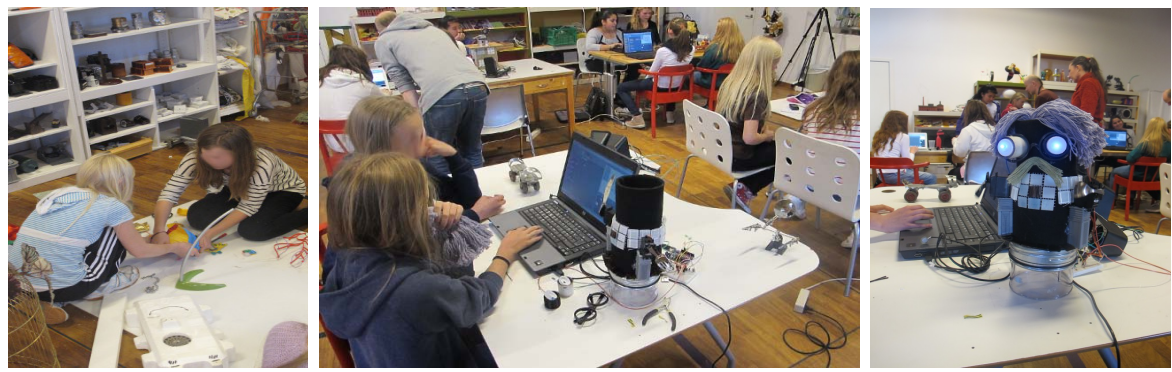

Fig. 2. Left, The physical part of the activity on ReMida Center. Middle, Children connecting the physical with the digital. Right, An example of interactive artworks (installations).

middle). The children completed and published in total six interactive works and eleven installations (see example, Figure 2 right) based on the software/hardware and the recycling materials of the center. Record of the childrens activities was kept through photographs, surveys, interviews and observation reports and used as data in this research.

\section{$3 \quad$ Preliminary Findings}

As aforementioned, a wide range of data was collected to address our research. In the data collection, a semi-structured interview guide was used in the personal in-depth interviews with the children. Interview questions were designed to probe different aspects of motivation and creativity. After the childrens interviews were collected (see examples of children's responses in Figure 1), we proceeded with a content anal-ysis. The content analysis procedures led us to several conclusions about the creative activities. Specifically, we can say that the creative development activities:

a) Raise awareness for technology,

b) Make the experience more intense,

c) Invite children to explore boundaries,

d) Increase collaboration and the exchange of views and ideas.

In addition to the qualitative study, a survey based on important aspects (con-structs) identified on the literature was implemented. Participants took the survey two days after the workshop, evaluating the following measures: Intention to Participate, Enjoyment, Satisfaction, Usefulness and Easiness. The level of enjoyment $(6.29 / 7)$ and satisfaction $(5.80 / 7)$ are high. The level of usefulness $(5.42 / 7)$ and easiness (5.53/7) are slightly lower. The participants intentions to participate in similar activities $(4.26 / 7)$ are not in at such a high level. In general we can conclude that childrens attitudes were very positive, but there is space for improving several aspects, like increasing their intention to participate. 


\section{Discussion and Conclusion}

In this paper we presented the results from the design, deployment and evaluation of OurToys program. Children engaged in programming languages (i.e., Scratch) and programmable hardware platforms (i.e., Arduino), which enabled them to engage in the world of creativity with digital enriched artifacts, like robots and interactive instal-lations.

The early results of our study showed that creative activities have certain and di-verse benefits to offer and improve childrens learning. In addition, children face these activities with positive attitude and great interest. However, several areas for improvement in the design and implementation of these activities exist.

The multiplicity of viewpoints the data yielded were useful as those provided in-sight and depth in the children's experiences, perspectives and opinions, and strength-ened this mixed method research. As creative activities are now widely used, an in-depth understanding of these activities in diverse and multiple settings has become a necessity.

We are in the process of extending our program to explore how programming in-tensive creative activities can offer benefits to children with impairments. Our hy-pothesis that will guide these future studies is that computing and creativity which are "extra languages" are even more important for people with communication impair-ments, like visual and hearing impairments. In view of the above we will take the advantage of (e.g., sign language) and introduce children with impairments into the world of the creative development via computing. In particular, our future work aims to produce a set of guidelines for how to customize digital creative technology for children with impairments.

Acknowledgements. The authors would like to thank the participants, P. Byesen, A. Eriksen I. Leftheriotis \& R. Proto. The project has been recommended by the Data Protection Official for Research, Norwegian Social Science Data Services.

\section{References}

1. Buechley, L., Eisenberg, M., Catchen, J., Crockett, A.: The LilyPad Arduino: Using Computational Textiles to Investigate Engagement, Aesthetics, and Diversity in Computer Science Education. In: Proc. CHI 2008, pp. 423-432. ACM Press (2008)

2. Cassell, J.: Towards a Model of Technology and Literacy Development: Story Listening Systems. Journal of Applied Developmental Psychology 25(1), 75-105 (2004)

3. Edwards, C., Gandini, L., Foreman, G.: The hundred languages of children: the Reggio Emilia approach to early childhood education, 2nd edn. Ablex Publishing, NJ (1998)

4. Jaccheri, L., Giannakos, M.N.: Open source software for entertainment. In: Herrlich, M., Malaka, R., Masuch, M. (eds.) ICEC 2012. LNCS, vol. 7522, pp. 604-607. Springer, Heidelberg (2012)

5. Papert, S.: Mindstorms: Children, Computers, and Powerful Ideas. Basic Books, New York (1980)

6. Price, S., Rogers, Y.: Lets get physical: the learning benefits of interacting in digitally-augmented physical spaces. Computers \& Education 15(2), 169-185 (2004) 